therefore, all conditions were combined into a single analysis of variance. In this case, all three variables reached statistical significance at the .05 level. These results indicate that, if anything, a larger illusion was present when the oblique line was imagined than when it was present objectively.

The results of these experiments clearly contradict any theory of the Poggendorff illusion which attempts to explain the illusion on the basis of processes that occur at the retinal level, and it appears that the theories proposed by Chiang (1968) and by Ganz (1966) are disqualified on this basis. The theories which argue that the Poggendorff illusion is caused by lateral inhibition between orientation detectors (Blakemore et al, 1970) are also challenged by these results, unless, of course, it is argued that an imagined oblique line is also mediated by an orientation detector. The idea that an orientation detector can be triggered by instructions to imagine a line of certain orientation is certainly novel and logically possible, but, to our way of thinking, it is not a very plausible alternative.

The results of this study are compatible with the assimilation theory of geometric illusions, which has been extended recently to the Poggendorff illusion (Pressey, 1971; Pressey \& Sweeney, 1972). The assimilation theory explains illusions on the basis of systematic distortions in the way focal and contextual information is processed. According to this theory, it would not matter whether an oblique line which is to be projected is real or imagined. The information, regardless of its source, will be distorted in a similar manner.

\section{REFERENCES}

Blakemore, C., Carpenter, R. H., \& Georgeson, M. A. Lateral inhibition between orientation detectors in the human visual system. Nature, 1970, 228, 37-39.

Burns, D. B. \& Pritchard, R. Geometrical illusions and the responses of neurones in the cat's visual cortex to angle patterns. Journal of Physiology, 1971, 213, 599-616.

Chiang, C. A new theory to explain geometrical illusions produced by crossing lines. Perception \& Psychophysics, $1968,3,174-176$.

Ganz, L. Mechanisms of figural after-effects. Psychological Review, 1966, 73, 128-150.

Pressey, A. W. An extension of assimilation theory to illusions of size, area, and direction. Perception \& Psychophysics, 1971, 9, 172-176.

Pressey, A. W., \& Sweeney, O. Some puzzling results on the Poggendorff illusion. Perception \& Psychophysics, 1972, 12, 433-437.

\section{NOTE}

1. Typical responses were "I thought the bottom dot was a clue to the point where we were to mark, so I marked all points straight across from it" or "I thought I was supposed to superimpose the oblique on the top (bottom) dot."

(Received for publication March 13, 1974.)

\title{
The stimulation-seeking motive: Relationship to conceptual category breadth
}

\author{
FRANK H. FARLEY, JAMES M. PETERSON, and THOMAS J. WHALEN \\ University of Wisconsin, Madison, Wisconsin 53706
}

A hypothesis that breadth of categorization would increase linearly with increases in the stimulation-seeking motive was tested on 43 males and 43 females, using Pettigrew's Category Width measure and a measure of individual differences in the stimulation-seeking motive. The results did not support the hron-1l. -

r work of Taylor and Levitt (1967). There was a slight trend toward between stimulation seeking and category breadth, but the and earlier work suggested the conclusion that there is no reliable seeking motive and conceptual category breadth.

notivation of king, arousal :perience has recently been substantially documented (Farley, 1971; Lester, 1969). Measures of arousal seeking have been shown to be related to preference for visual complexity, 
Table 1

Mean Sensation Seeking Scores for the Various Breadth-of-Categorization Groups

\begin{tabular}{lccc}
\hline Categorizer Type & Males & Females & Overall \\
\hline Broad & 86.7 & 75.2 & 81.0 \\
High Moderate & 78.9 & 62.1 & 70.5 \\
Low Moderate & 89.9 & 81.8 & 85.9 \\
Narrow & 69.2 & 51.8 & 60.5 \\
Overall & 80.7 & 67.6 & \\
\hline
\end{tabular}

with high "arousal seekers" preferring complexity over simplicity (Zuckerman, Neary, \& Brustman, 1970), tolerance of sensory deprivation conditions, with high-arousal seekers demonstrating lower tolerance (Zuckerman, Persky, Hopkins, Murtaugh, Basu, \& Schilling: 1966; but see Smith \& Myers, 1966; and Zuckerman, Persky, Link, \& Basu, 1968), visual acuity, with high-arousal seekers demonstrating greater visual acuity (Palmer, 1970), and tolerance thresholds for (auditory) noise, with high-arousal seekers being more able to tolerate greater noise intensities (Farley \& Kline, 1972). The high-arousal seeker not only seeks more stimulation and more complex and varied stimulation, relative to the low-arousal seeker, but he also generates more varied responses in a task allowing for degrees of repetition or variety of responding (Farley, 1971). Little research, however, has been reported on the contribution of individual differences in arousal seeking to more specifically cognitive processes. Slight relationships have been reported between stimulation seeking and academic aptitude measures (Kish \& Busse, 1968; Kish \& Donnenwerth, 1972; Pemberton, 1971) and slight-to-strong relationships with measures of creativity and innovativeness (Acker \& McReynolds, 1967; Davis, Peterson, \& Farley, 1974; Farley, 1965, 1971). Taylor and Levitt (1967) have reported a significant relationship between stimulation seeking and breadth of categorization, using the Pettigrew (1958) Category Width Scale (CWS). Arousal or stimulation seeking was positively linearly related to breadth of categorization, although this relationship was significant only for males. A U-shaped relationship was suggested for females, with extreme categorizers (broad and narrow) having lower stimulation-seeking scores than intermediate categorizers (high and low moderate). The Taylor and Levitt study is of particular interest as the only study of the relationship of the preference for varied stimulation to cognitive categorizing behavior. The results for males appear reasonable where theoretical expectations are concerned, but the lack of significant relationship for females is puzzling. The suggested U-shaped function relating category breadth to arousal-seeking scores was not specifically tested for significance; a Pearson product-moment correlation was computed between the two sets of scores, and was found to be not significant. One problem, however, is that this procedure cannot detect significant curvilinearity. Another problem in this study lay in the choice of stimulation-seeking measure. The authors employed the Sensation-Seeking Scale (SSS) (Zuckerman, Kolin, Price, \& Zoob, 1964), which has been used more extensively than any other comparable measure (Farley \& Haubrich, 1974) and was used in most of the studies cited above. However, unlike most of the studies which have used the 22-item form of the test recommended for use with both sexes, Taylor and Levitt employed the little-used longer form, which has only rarely been entered into analyses of perceptual, motivational, and cognitive variables. It might also be noted that the sex differences discussed above may have been due to differential test reliabilities between groups attributable to the large disparity in group Ns, with 43 males being compared to 26 females.

The foregoing considerations suggested the necessity of replicating the Taylor and Levitt study, but with the 22-item form of the SSS and equal Ns between sexes.

\section{METHOD}

Volunteers were recruited primarily from an undergraduate course and graduate seminar at the University of Wisconsin. Eighty-six Ss completed the experiment (43 females, 43 males).

Category breadth was taken as the total score on the CWS. The possible range on this test is from 0 to 120 points, with high scores indicating broad categorization. Where the SSS was concerned, the Tàylor and Levitt procedure of converting the scores to a possible range of 0 to 120 points was used. This was accomplished by assigning each SSS response 5.45 points.

Order of administration of the questionnaires was counterbalanced. Assignment of Ss into breadth of categorization groups was done without knowledge of SSS scores.

\section{RESULTS}

The range in breadth of categorization scores was 12-112, which compares to 13-115 for Taylor and Levitt. Mean CWS scores for males $(73.2, \mathrm{~N}=43)$ and females $(64.7, \mathrm{~N}=43)$ were comparable with the Taylor and Levitt data as well as those of Pettigrew (1958). Males were significantly broader categorizers than females $(\mathrm{t}=2.1745, \mathrm{df}=85, \mathrm{p}<.05)$.

The Ss were ranked and divided into four groups, collapsed across sex, on the basis of their CWS scores, following the procedures of Taylor and Levitt. The mean CWS scores and Ns for the various groups, with the directly comparable Taylor and Levitt means and Ns in parentheses, were: broad categorizers, $\bar{X}=91.5, \mathrm{~N}=20$ $(\bar{X}=94.6, N=17)$; high-moderate categorizers, $\bar{X}=$ 73.6, $\mathrm{N}=22(\overline{\mathrm{X}}=79.8, \mathrm{~N}=18)$; low-moderate categorizers, $\bar{X}=64.9, N=22(\bar{X}=69.7, N=17)$; and narrow categorizers, $\overline{\mathrm{X}}=47.7, \mathrm{~N}=22(\overline{\mathrm{X}}=50.0, \mathrm{~N}=$ 17).

The mean SSS scores for the four CWS groups for each sex are presented in Table 1 .

An inspection of overall mean SSS scores in Table 1 fails to confirm the "linear trend" relationship between breadth of categorization and sensation seeking reported 
Table 2

Mean Category Width Scores for the Various Sensation Seeking Groups

\begin{tabular}{cccc}
\hline Sensation Seeking & Males & Females & Overall \\
\hline High & 78.0 & 67.4 & 72.7 \\
High Moderate & 79.1 & 75.7 & 77.5 \\
Low Moderate & 70.2 & 59.3 & 64.7 \\
Low & 64.6 & 61.6 & 63.1 \\
Overall & 73.2 & 65.8 & \\
\hline
\end{tabular}

by Taylor and Levitt. However, a 2 by 4 random blocks analysis of variance was applied to the data with results as follows: Sex MS $=129.79$, $\mathrm{df}=1 / 78, \mathrm{~F}=9.29$ $(\mathrm{p}<.01)$; category breadth $\mathrm{MS}=92.09, \mathrm{df}=3 / 78, \mathrm{~F}=$ $6.59(\mathrm{p}<.01)$; interaction $\mathrm{MS}=3.47$, df $=3 / 78, \mathrm{~F}=$ 0.25 (n.s.); within $\mathrm{MS}=13.97$, $\mathrm{df}=78$. From the foregoing, it can be seen that both sex and category width main effects were significant. The raw (untransformed) overall SSS mean for females was 12.37 $(\mathrm{SD}=4.30)$ and for males, $14.81(\mathrm{SD}=3.69)$. Scheffé post hoc pairwise comparisons (set at $\mathrm{p}<.05$ ) among categorization group means (collapsed across sex) were performed. Here the only significant differences were between broad and narrow categorizers (critical difference at $.05=3.29$, obtained difference $=3.76$ ) and between low-moderate and narrow categorizers (critical difference at $.05=3.20$, obtained difference $=4.64)$. In both of the foregoing cases, the comparisons were based on raw SSS scores.

Product-moment correlation coefficients were computed between sensation-seeking and category width scores, with the obtained values being .22 (n.s.) for females and $.35(\mathrm{p}<.05)$ for males. The direction of the difference in correlations here was the same as that reported by Taylor and Levitt (the comparable correlations being .13 and .65 , respectively), but the present correlation for males was considerably smaller than that of Taylor and Levitt.

\section{DISCUSSION}

The present study has clearly failed to replicate the findings of Taylor and Levitt (1967), in that a linear relationship between sensation seeking and the four categorization conditions was not obtained. Broad, high-moderate, low-moderate, and narrow categorizers ranked $2,3,1,4$, respectively, in sensation-seeking scores, rather than $1,2,3,4$, as found by Taylor and Levitt. In accord with the latter authors, the broad categorizers were significantly higher in sensation seeking than the narrow categorizers. But the low moderates were, and the high moderates were not, significantly different in SSS scores from the narrow categorizers.

In the hope of shedding light on these anomolous findings, the data were reanalyzed, taking sensation seeking as the independent variable for blocking and CWS scores as the dependent variable. This replotting of the data resulted in somewhat of an inverted-U pattern of cell means, as indicated in Table 2. A second 2 by 4 random blocks analysis of variance was conducted on the reconstituted data, the results of which were as follows: Sex MS = 1,044.21, $\mathrm{df}=1 / 78, \mathrm{~F}=3.30(\mathrm{p}<.05)$; SSS MS $=972.77, \mathrm{df}=3 / 78, \mathrm{~F}=3.07(\mathrm{p}<.05) ;$ interaction MS
$=103.42, \mathrm{df}=3 / 78, \mathrm{~F}=0.33$ (n.s.); within $\mathrm{MS}=316.39$, $\mathrm{df}=$ 78. Scheffé post hoc comparison (set at $p<.05$ ) among the means (collapsed across sex) of these data from Table 2 were conducted, with a significant difference being found between the combination of low and low-moderate groups vs the high-moderate group. Comparisons of the low and low-moderate groups vs the high and high-moderate groups, and the low, low-moderate, and high groups vs the high-moderate group, were not significant at or beyond the .05 level. In addition, no comparison between any of the single group means attained significance.

The foregoing reanalysis of the data indicates that as sensation-seeking scores increased, the hint of an inverted-U relationship to category width was suggested. The greatest breadth-of-categorization scores were found in the high-moderate sensation-seeking group, with this group being significantly broader categorizers than a combination of the low and low-moderate sensation-seeking groups. The lack of comparable results between the present study and that of Taylor and Levitt (1967), even though samples and procedures were highly comparable, suggests that the relationship of sensation seeking and breadth of categorization is not reliable.

\section{REFERENCES}

Acker, M., \& McReynolds, P. The Obscure Figures Test: An instrument for measuring "cognitive innovation." Perceptual \& Motor Skills, 1965, 21, 815-821.

Davis, G. A., Peterson, J. M., \& Farley, F. H. Attitudes, motivation, sensation-seeking, and belief in ESP as predictors of real creative behavior. Journal of Creative Behavior, 1974, in press.

Farley, F. H. Creativity and the sensation-seeking motive. Unpublished study, University of London, England, 1965.

Farley, F. H. Measures of individual differences in stimulation seeking and the tendency toward variety. Journal of Consulting \& Clinical Psychology, 1971, 37, 394-396.

Farley, F. H., \& Haubrich, A. S. Response set in the measurement of stimulation-seeking. Educational \& Psychological Measurement, 1974, in press.

Farley, F. H., \& Kline, K. Noise and light tolerance thresholds and the stimulation-seeking motive. Unpublished study University of Wisconsin, Madison, 1972.

Kish, G. B., \& Busse, W. Correlates of stimulus-seeking: Age, education, intelligence, and aptitudes. Journal of Consulting \& Clinical Psychology, 1968, 32, 633-637.

Kish, G. B., \& Donnenwerth, G. V. Sex differences in the correlates of stimulus seeking. Journal of Consulting \& Clinical Psychology, 1972, 38, 42-49.

Lester, D. (Ed.) Explorations in exploration. New York: Van Nostrand, 1969.

Palmer, R. D. Visual acuity and stimulus-seeking behavior Psychosomatic Medicine, 1970, 32, 277-284.

Pemberton, W. A. Further dimensions of sensation seeking. Paper presented at Delaware Psychological Association meeting, May 1971 .

Pettigrew, T. F. The measurement and correlates of category width as a cognitive variable. Journal of Personality, 1958, 26 532-544.

Smith, S., \& Myers, T. I. Stimulation seeking during sensory deprivation. Perceptual \& Motor Skills, 1966, 23, 1151-1163.

Taylor, R. L., \& Levitt, E. E. Category breadth and the search for variety of experience. Psychological Record, 1967, 17, 349-352.

Zuckerman, M., Kolin, E. A., Price, L., \& Zoob, I. Development of a Sensation-Seeking Scale. Journal of Consulting Psychology, 1964, 28, 477-482.

Zuckerman, M., Neary, R. S., \& Brustman, B. A. Sensation-Seeking Scale correlates in experience (smoking, drugs, alcohol, "hallucinations," and sex) and preference for complexity (designs). Proceedings, 78th Annual Convention, American Psychological Association, 1970.

Zuckerman, M., Persky, H., Hopkins, T. R., Murtaugh, T., Basu G. K., \& Schilling, M. Comparison of stress effects of perceptual and social isolation. Archives of General Psychiatry, 1966, 14, 356-365.

Zuckerman, M., Persky, H., Link, K. E., \& Basu, G. K. Experimental and subject factors determining responses to sensory deprivation, social isolation and confinement. Journal of Abnormal Psychology, 1968, 73, 183-194.

(Received for publication March 25, 1974.) 